This is an author produced version of a paper published in Maturitas. This paper has been peer-reviewed but does not include the final publisher proof-corrections or journal pagination.

Citation for the published paper:

Li, Cairu and Borgfeldt, Christer and Samsioe, Göran and Lidfeldt, Jonas and Nerbrand, Chirstina

"Background factors influencing somatic and psychological symptoms in middle-age women with different hormonal status.

A population-based study of Swedish women."

Maturitas. 2005 Nov-Dec;52(3-4):306-18.

http://dx.doi.org/10.1016/j.maturitas.2005.05.005

Access to the published version may require journal subscription.

Published with permission from: Elsevier 


\section{Background factors}

\section{influencing somatic and psychological symptoms}

\section{in middle-age women with different hormonal status}

\section{A population-based study of Swedish women.}

Cairu Li PhD, MD a, Christer Borgfeldt PhD, MD b, Göran Samsioe PhD, MD b, Jonas Lidfeldt $\mathrm{PhD}, \mathrm{MD}^{\mathrm{c}}, \quad$ Chirstinal Nerbrand $\mathrm{PhD}, \mathrm{MD}^{\mathrm{c}}$
a, Department of Community Medicine, Malmö University Hospital, Sweden
b. Department of Obstetrics \& Gynecology, Lund University Hospital, Sweden
c. Department of Community Medicine, Lund University Hospital, Sweden

\footnotetext{
*Address for correspondence:

Cairu Li

Department of community medicine

Malmö University Hospital, Sweden

Phone: +46-40-332956, Fax: +46-40-336215

E-mail: cairu.li@smi.mas.lu.se
} 


\begin{abstract}
Objective: To analyse the influence of socio-demographic characteristics and environmental factors on self-reported somatic and psychological symptoms among middle-aged Swedish women.
\end{abstract}

Methods: A total of 6917 women living in the Lund area of southern Sweden were participates of this study. They completed a generic questionnaire pertaining to sociodemographic characteristics, lifestyle factors and current health related problems. According to hormonal status, the participants were subdivided into three groups, i.e. premenopause, postmenopause and peri- or postmenopausal women with hormone replacement therapy $(\mathrm{HRT})$.

Results: By using multiple logistic regression models, a high risk for somatic symptoms was independently associated with unemployment, no exercise, un-married, high body weight, and diseases affecting the cardiovascular system as well as a history of cancer. . Psychological symptoms were independently associated with higher educational level, unemployment, no exercise, un-married, heavy smoking habits ( $>15 \mathrm{cig} /$ day), weight gain, and a history of cancer. In addition, the background factors seemed to have less impact on symptoms among women who used HRT.

Conclusion: Socio-demographic characteristics, lifestyle factors and concurrent health problems appear to have influences on the frequency and the number of somatic and psychological symptoms in middle-age women. Hormone replacement therapy seems to be able to counteract negative impacts caused by un-healthy lifestyle and other health problems. 
Key words: Psychosomatic symptoms, socio-demographic factors, lifestyle factors, midlife women, HRT. 


\section{Introduction}

There is general consensus that women experience a wide range of physical and psychological symptoms during their midlife ${ }^{(1,2)}$. In the search for etiology, huge efforts have been made to identify potential influences on symptomatology by aging progress, endocrine changes, demographic characteristics, psychosocial factors, environmental conditions, ethnic-difference as well as differences between countries. A clear etiologic relationship has been found between vasomotor symptoms/genital atrophic disorders and estrogen deficiency during women's menopausal period $(3,4)$. These symptoms are widely regarded as typical for menopause. However, findings have been more controversial as to the relation between menopausal status and other physical or emotional problems that are frequently encountered by women during their midlife $(5,6)$.

Several somatic and psychological disturbances occur frequently during women's midlives, especially at the first year of menopause, such as irritation, depressive mood, sleeping problems, fatigue, headache, muscular-skeletal pains and join problems (6). Yet, these symptoms are considered as atypical for menopause because the prevalence of these symptoms is not only limited to the middle age of women. In addition, the occurrences of these symptoms have no direct relation to hormonal changes (5).

In recent years, demographic characteristics, psychosocial issues (stress, employment conditions, total work burden, number of children, etc) and lifestyle factors are considered as important determinants for women's symptomatology $(6,7,8,9)$. These components might also exert an influence by modifying women's experience of symptoms. However, the information on this topic is limited, particularly in populationbased cohorts. 
This study is a part of a large population-based study - 'Women's Health in the Lund Area (WHILA)', which is a cohort of Swedish middle-age women. In order to delineate the demographic and environmental influence on psychosomatic issues, we analyzed and quantified the impacts of socio-demographic characteristics, medical histories and lifestyle factors on the basis of frequency and severity of symptoms among middle-aged women. In addition, the investigations also explore whether the association between symptoms and background factors differs in women with different hormonal status. 


\section{Material and methods}

Participants of the 'Women's Health in the Lund Area' (WHILA)' cohort were eligible for the present study. Detailed information of the WHILA study has been described previously (6). In brief, the purpose of WHILA project was to evaluate health status, lifestyles, as well as social and medical factors among the middle-aged women who were 50-64 years old and inhibits in the southern part of Sweden. All women were offered a health assessment program, including a mailed generic self-administered questionnaire tied to a mammography and laboratory examinations performed at a screening center. The study was approved by the Local Ethics Committee of Lund University, Sweden and by the Data Registry Authority (Datainspektionen) in Stockholm.

\section{Study population and groups}

From 1996 to 2000, women, born between December 2, 1935 and December 1, 1945 and living in the Lund area by December 1, 1995, were invited to the WHILA study $(n=10870)$. The total numbers of participants were 6,917 yielding a response rate of $64 \%$. The main reasons for non-response were immigrants with poor knowledge of Swedish, moving out of the community prior to appointment offered, refusal, severe disease or death. Age distribution was similar between respondents and non-respondents. More nonrespondents than respondents died during the period $1995-1998(2.6 \%$ vs. $0.2 \%, \mathrm{p}<$ $0.001)$, as well as during the following two years, $1999-2000(1.5 \%$ vs. $0.3 \%, p<0.001)$. The main causes of death were cancer and cardiovascular disease. 
According to the hormonal status, the participants were divided into three groups, i.e. pre-menopause (PM), post-menopause (PMO) and peri-or post-menopausal women with current HRT use (PMT). The classifications were detailed by the previous study ${ }^{(6)}$.

\section{Self-reported data collection}

The generic questionnaire contained 104 questions concerning socio-demographics, health problems, menopausal status, hormone therapy (HRT) administration and quality of life issues. Most of the questions had been validated and used previously (6). All participants underwent a personal interview, which was carried out by a specially trained nurse or midwife to endorse and correct questionnaire replies.

The questionnaire was made up of two parts:

\section{Part I. Background variables}

Background variables included socio-demographic characteristics, such as chronological age, marital status, education levels, employment and working condition. The level of education was classified as basic ( $<7$ years of education), secondary ( $7-12$ years) and university/college levels. The working conditions were based on the degrees of physical activity in work. Three categories were subdivided, including sedentary work (e.g. desk work, teacher), light activity work (e.g. clerks, shop attendant) and heavy activity work (e.g. agricultural work, heavy industrial work). Several medical related questions were also involved, for instance, history of previous gynecologic surgery (hysterectomy and/or oophorectomy), history of cancer, history of disease affecting cardiovascular system [hypertension (HT), diabetes mellitus (DM), deep venous thrombosis (DVT), acute myocardial infarction (AMI) or cerebral vascular lesion (CVL)]. In addition, reproductive 
events were also evaluated, such as age of menarche, intervals of menstruation (days/monthly), pregnancies (yes/no), number of children, age at menopause, history of use oral contraceptives and/or HRT.

Physical activities during leisure time were categorized into three levels, i.e. no regular exercises, light exercises (e.g. walk, cycling or gardening for at least 2-4 hours/week) and vigorous exercises (competitive exercises, such as running, swimming, tennis or gymnastics for more than 3 hours/week). Smoking status was classified as non-smoking, light smoking ( $\leq 14$ cigarettes/daily) and heave smoking $(\geq 15$ cigarettes/daily). Alcohol consumption was also grouped into three categories, i.e. non alcohol, light alcohol consumption $(<15 \mathrm{ml}$ of $100 \%$ alcohol per week) and high alcohol consumption $(\geq 15 \mathrm{ml}$ of $100 \%$ alcohol per week).

Measurements of body mass index (BMI), Waist-to-Hip Ratio (WHR) (10), self-reported weight gain (weight increased from 25 years old up to now) and weight change (decreased or increased weight more than 5 kilos during the last 5 years) were incorporated.

Part II. Self-reported psychosomatic symptoms

Somatic symptoms

There were 19 questions about somatic symptoms which had been experienced by women during the preceding three months. The symptoms were headache, dizziness, impaired hearing, eye problems, breathlessness, coughing, chest pain, abdominal pain, nausea, diarrhoea, constipation, loss of appetite, joint problem, back ache, leg pain, feeling of chilly, sweats, loss of weight and difficulty in passing urine. The answer to each question was 'yes' or 'no'. According to the number of the positive answers (yes), 
the numbers of somatic symptoms was categorized into three degrees: slight (0-2), moderate (3-7) and severe (8-19).

Psychological symptoms

There were 10 questions concerning psychological symptoms, including fatigue, sleeping disturbance, irritability, nervousness, restlessness, over-stressed, easy to cry, feeling blue or depressed, difficult to relax and impaired concentration. Women were asked whether the symptoms were bothersome or had interfered in their life during the preceding three months. The answer to each question was 'yes' or 'no'. According to the number of positive answers (yes), the number of psychological symptoms was categorized into three degrees: slight (0-1), moderate (2-4) or severe (5-10).

\section{Statistical approach}

In the analysis, the prevalence of the somatic and psychological problems was presented only for the symptoms which were commonly reported by the women. In addition, we combined the symptoms of stomach pain, nausea, diarrhoea and constipation into one variable as 'gastrointestinal symptoms'. However, the severity of symptoms was assessed on the basis of the whole listed symptoms in the questionnaire.

The assessments on the risk of symptomatology in relation to background characteristics were performed by two steps. In the first step, the prevalence of symptoms was compared between the categories of each background factor by using chi-square test and unadjusted logistic regression model.

Forward stepwise multiple regression models were applied in the second step to identify the independent risk factors on symptomatology. In the model, 16 background variables 
were included, i.e. age, age at menopause, married status, education, employment, working condition, smoking status, alcohol consumption, physical exercise, histories of hysterectomy, oophorectomy, history of cancer or history of diseases affecting the cardiovascular system (i.e. HT, DM, DVT, AMI, CVL), BMI, WHR and recent weight gain. Variables with p-values $>0.10$ were removed from the stepwise model. All comparisons were two-sided, and a 5\% level of significance was used. The statistical analyses were conducted using the computer soft ware SPSS TM (11.0.0) (SPSS Inc., Chicago, IL, USA). 


\section{Results}

In the total of 6917 women, $9 \%(n=623)$ were pre-menopausal (PM), 52\% postmenopausal $(\mathrm{n}=3596)(\mathrm{PMO})$ and 39\% current HRT users $(\mathrm{n}=2698)(\mathrm{PMT})$. The mean age was $56 \pm 3.0$ years old (ranging from 50 - 64 years old) with Caucasian ethnicity $(96 \%)$.

The differences of background characteristics between the groups have been reported elsewhere (6). Briefly, premenopausal women and women who used HRT had more healthy lifestyle and less health-related problems than those of postmenopausal women. In addition, a high rate of consuming medical surveillance and medication was found in HRT users (6).

The results from the sub-group analyses were restricted to the PMO and PMT groups only since the number of subjects in PM group was too small to reach the sufficient statistical power.

There was no significant association between reproductive events and psychosomatic symptoms in this cohort.

\section{Frequency of somatic symptoms and risk factors analysis}

Several symptoms were commonly reported by women, including leg and/or back ache (47\%), headache (46\%), joint problems (45\%), eye disorders (33\%), dizzy $(26 \%)$, impaired hearing (22\%), short breath (21\%), breast tenderness (19\%) and gastrointestinal symptoms $(17 \%)$.

The majority of background components were clearly related to the frequency and number of somatic symptoms (Table 1). By using the logistic regression analyses, 
somatic symptoms were negatively affected by the variables of unemployment, secondary education, heavy smoking, oophorectomy, hysterectomy, overweight, obesity, weight change, weight gain, history of cardiovascular diseases or a history of cancer. Age had impact on the frequency of symptom but not on the number of symptoms. For example, joint-skeletal symptoms were increased with age, but headache was just the reverse (Table 1).

Marriage, light and intense physical exercises and alcohol consumption were associated with lower frequency of symptoms.

In total cohort, the forward stepwise regression model showed that several variables were independently affecting the risk of somatic symptoms which was compared between high numbers and low numbers of symptoms, such as marital status, education, employment, exercise, recent and long time weight gain, diseases affecting the cardiovascular system and a history of cancer (Table 2).

In the sub-group analyses, the majority results in PMO group were similar to those of the total cohort except marital status and BMI (Table 2). In PMT group, the factors of education, employment, BMI and cancer did not show influence on symotomatology (Table 2).

\section{Frequency of psychological problems and risk factor analyses}

Emotional problems, such as irritation, overstressed and sleeping disorders were encountered by more than $40 \%$ of women in the total, and over half of women had a feeling of fatigue. Depressed mood was reported by over $60 \%$ of women, which also 
coincided with non-marriage, unemployment, non-exercise, heavy smoking, obesity, weight change, weight gain, or chronic disease (Table 3).

The most important determinants that impaired the whole profile of psychological symptoms were high level of education, unemployed, heavy smoking, hysterectomy, overweight and obesity, weight gain (increased weight more than $5 \mathrm{~kg}$ during last 5 years), weight change (from 25 years old up to now), and a history of diseases affecting the cardiovascular system (Table 3). However, the variables of getting older, marriage, part-time employment and regular exercises appeared to have a positive influence on psychological symptoms (Table 3).

By utilizing forward stepwise regression model, the risk of symptoms in the total cohort worsened in line with higher education, unemployment, heavy smoking habits ( $>15$ cig/day), weight gain, weight change and a history of cancer (Table 4). Physical exercise seemed to lower the risk of emotional disorders. In the sub-group analyses the results were similar, but in the PMO group marriage and excessive weight gain $>20 \mathrm{~kg}$ last 25 years were independent background factors. In the PMT group, regular exercise showed a lower risk and weight gain higher risk for psychological symptoms (Table 4). 


\section{Discussion}

This study is a population-based survey to evaluate health-related risk factors on the basis of socio-demographic characteristics and lifestyle factors among middle-aged women. As host and environmental factors are often interrelated and interact on each other, unadjusted results may not be reliable. Therefore, the predicted risk factor analyses in this study were performed using a wide range of adjustments for confounding factors that conceivably modify the relations of dependent and independent variables.

By using covariate-adjusted analyses, the majority of socio-demographic characteristics, lifestyle factors and health related problems appear to influence the frequency and number of psychosomatic symptoms. We found that the factors of unemployment, current smoking, high BMI, weight gain, history of disease or cancer could significant worsen the risk of symptoms. In contrast, the physical activity and married life were associated with a low risk of symptoms.

In relation to different hormonal status, some results were divergent. Several factors which showed an adverse impact on the risk of symptoms in women without HRT had no impact among women with HRT. The divergent results may be attributed to the beneficial effect of estrogen on women's physical fitness and emotions.

\section{Marriage}

It is known that marriage plays an important role in woman's physical and mental health (11). The findings in this study revealed that married life contributed to less severe somatic and psychological symptoms, which is consistent with the previous literature $(11,12)$. Married life has been demonstrated to be a positive factor for health. Marital 
dissolution alone, or together with low marital quality, were associated with worsened mental and physical condition and increased use of mental health service whereas marital harmony was accompanied with better sleeping patterns, lower depressive symptoms and reduced health care consumption (12). A previous study found the relation between marital satisfaction and health was more prominent in women than in men because women in unhappy marriages reported more mental and physical health problems than men (13).

\section{Education}

The severity of psychological symptoms in this cohort tended to increase coincided with the elevating educational attainments. Over $50 \%$ of women with a university education complained of an overstressed life and more than $60 \%$ felt exhausted. The high prevalence of emotional problems may be due to the fact that women who have a higher education are often engaged in a professional job, which usually is stressful and with higher psychological demands and expectations.

However, our findings are contrary to the data reported in the literature, in which the high prevalence of psychological symptoms appeared frequently in the low-educated women $(8,14)$. The inconsistencies may be attributed to differences in methodology, such as criteria, items and the degrees of symptoms, the number of subjects or lacking of extended adjustments when the predictive risk factor analyses were carried out. In addition, the relation of education level and women's psychological problems were not significant among the women who were HRT users. This exception may be attributed to the effects of estrogen. It is no doubt that estrogen may diminish anxiety, enhance mood 
and subjective sense of well-being, and estrogen may also blunt the stress-induced response via suppressing the secretion of stress hormones (cortisol and adrenaline) $(15,16)$, which may be one reason to explain why women with a stressful and psychologically demanding job are willing to use HRT (17).

\section{Physical activity}

Physical exercises have beneficial effects on women's mood, general well being, sleeping disorders and even on cognitive functions $(18,19)$. Low physical activity is generally considered a risk factor for cardiovascular disease, obesity and osteoporosis. We found that regular physical exercise, either light or vigorous, was independently associated with both lower somatic and psychological symptoms. These findings confirm that physical activities do not only have a positive influence on psychosomatic status, but also seem to reflect the general health status of women. The healthier the woman is, the more physical activities she usually performs.

\section{Smoking habits}

In accordance with other epidemiological reports $(20,21,22)$, women with smoking habits had higher prevalence of depressive mood $(62 \%)$ and feeling of fatigue $(71 \%)$. We also found that cigarette smoking was an independent risk factor for psychological symptoms. This impact seemed to be dose-dependent.

Nicotine is the primary addictive substance in tobacco. In a previous animal experimental study, administration of nicotine in low doses showed an anxiolytic effect, whereas higher doses had an anxiogenic effect (23). The findings in the human studies points 
toward that nicotine might act as an antidepressant. It has been observed that depressive symptoms were improved by treatment with nicotine parch (24). It was also reported that depressed individuals were more likely to smoke than those with no history of depression $(49 \%$ vs. $22-30 \%)(20)$. Therefore, it is possible that women with emotional problems may attempt to self-treat mood disorders by smoking. On the other hand, withdrawal of nicotine may in turn cause or worsen psychological problems, in particularly in the women with previous depression episodes (22). In addition, it was interesting to find that smoking did not increase the psychological symptoms in women who used HRT. The distinction could be attributed to the treatment effects of HRT, especially by the route of administration. In practice, it is common to administrate a transdermal patch of estrogen to women who are smokers because smoking can affect estrogenic metabolic pathway in the liver resulting in lower or nonestrogenic metabolites (25). However, this first-passage effect in the liver can be avoided by use of the transdermal route, which has been showed better treatment effects than the oral route $(26)$.

\section{Body weight}

Higher body mass has been identified as a health risk factor for a number of chronic illnesses, i.e. cardiovascular diseases, diabetes mellitus, gall bladder disease, cancer, arthritis, and so forth $(27,28)$, which are further affirmed by the present study. Obese women had not only a higher prevalence of CVD related diseases ( $43 \%$ vs $18 \%$, $\mathrm{p}<0.001)$ compared with normal weight women, but also a higher rate of hysterectomy ( $16 \%$ vs $10 \%, p<0.001)$ and oophorectomy $(10 \%$ vs $6 \%$, p $<0.001$, data not shown). The 
prevalence and intensity of psychological symptoms were also associated with high values of BMI and WHR, but the impact was weak and not independent. Furthermore, nearly half of the women (43\%) reported that the weight gain occurred during the years of menopause transition, which further underscores the most marked weight increase in women appears at the time of menopause $(29,30)$. Weight increase has a positive correlation with the risk of cardiovascular diseases. It has been documented in a longitudinal study that if body weight increases more than $5 \mathrm{~kg}$ there is a significant excessive risk of developing coronary heart disease (CHD), and the risk of CHD increased by $3.1 \%$ for each kilogram of weight gain (31). Consistent with pervious studies, we found that the number of somatic symptoms increased significantly when weight gain was more than $5 \mathrm{~kg}$, and a remarkable deterioration of psychological symptoms was found if weight gain increased up to $20 \mathrm{~kg}$. Those adverse impacts were more striking during the period from later perimenopausal years to early postmenopausal years. As a whole, body weight gain more than $5 \mathrm{~kg}$, especially during menopause transition, increases the risk of developing both somatic and psychological symptoms.

\section{Study limitations}

The drop out analysis in this study revealed that the rate of mortality during the study period was higher in non-responders than that in responders. This finding may indicate that non-responders probably had a poorer health status compared with the responders. A poor health status is often accompanied with more symptoms and also at a higher degree of discomfort. This suggests that the number of symptoms and the degree of symptom may be even worse in the total population than in the investigated cohort. 


\section{Conclusion}

Socio-demographic characteristics, lifestyle factors and concurrent health problems appear to have modifiable influences on the frequency and number of somatic and psychological symptoms in middle-age women. Hormone replacement therapy seems to be able to counteract negative impacts caused by un-healthy lifestyle and other health problems. 


\section{Acknowledgement}

This study was supported by grants from the " De kvinnliga och manliga övergångsåren ", and Region Skane, Sweden. 


\section{References}

1, Avis NE, Kaufert PA, Lock M, McKinlay SM, Vass K. The evolution of menopausal symptoms. Baillieres Clin Endocrinol Metab 1993; 7: 17-32.

2, Dennerstein L, Smith AM, Morse C, et al. Menopausal symptoms in Australian women. Med J Aust 1993; 159 (4): 232-6.

3, Dennerstein L, Dudley EC, Hopper JL, Guthrie JR, Burger HG. A prospective population-based study of menopausal symptoms. Obstet Gynecol 2000; 96: 351-8.

4, Avis NE, Stellato R, Crawford S, et al. Is there a menopausal syndrome? Menopausal status and symptoms across racial/ethnic groups. Soc Sci Med 2001; 52: 345-56.

5, Hunter, M., Battersby, R. and Whitehead, M. Relationship between psychological symptoms, somatic complaints and menopausal status. Maturitas, 1986; 8: 217-228.

6, Li C, Kittisak W, Samsioe G, et al. Health profile of middle aged women. A population based study of Swedish women. The women's Health in Lund Area (WHIL) study. Human reproduction 2002; 17: 1379-1385.

7, Gold EB, Sternfeld B, Kelsey JL, et al. Relation of demographic and lifestyle factors to symptoms in a multi-racial/ethnic population of women 40-55 years of age. Am J Epidemiol 2000; 152: 463-473.

8, Kuh DL, Wadsworth M, Hardy R. Women's health in mid-life: the influence of the menopause, social factors and health in earlier life. Br J Obstet Gynecol 1997; 104: 923-933.

9, Emslie C, Hunt K, Macintyre S. Gender, work-home conflict, and morbidity amongst white-collar bank employees in the United Kingdom. Int J Behav Med. 2004;11:127-34. 
10, Burton BT, Foster WR, Hirsch J, van Itallie TB. Health implications of obesity: an NIH consensus development conference. Int J Obes 1985; 9: 155-69.

11, Joung M. The relationship between marital status and health. Ned Tijdschr Geneeskd 1997; 8, 141(6): 277-282.

12, Prigerson HG, Maciejewski PK, Rosenheck RA. The effects of marital dissolution and marital quality on health and health service use among women. Med Care 1999; 37 (9): 858-873.

13, Levenson RW, Carstensen LL, Gottman JM. Long-term marriage: age, gender, and satisfaction. Psychol Aging 1993; 8 (2): 301-31

14, Gold EB. Demographics, environmental influences, and ethnic and international differences in the menopausal experience. In Lobo RA, eds. Treatment of the postmenopausal women. Basic and clinical aspects. Philadelphia: Lippincott Williams \& Wilkins,1999; 189-201.

15, Deane R, Chummun H, Prashad D. Differences in urinary stress hormones in male and female nurses at different ages. Journal of Advanced Nursing 2002; 37: 304-310. 16, Komesaroff PA, Esler MD, Sudhir K. Estrogen supplementation attenuates glucocorticoid and catecholamine responses to mental stress in perimenopausal women. $\mathrm{J}$ Clin Endocrinol Metab 1999; 84: 606-610.

17, Collins A, Landgren BM. Psychosocial factors associated with the use of hormonal replacement therapy in a longitudinal follow-up of Swedish women. Maturitas 1997; 28: $1-9$. 
18, Collins A, Landgree BM. Reproductive health, use of estrogen and experience of symptoms in perimenopausal women: a population-based study. Maturitas 1995; 20: 101111.

19, Slaven L, Lee C. Mood and symptom reporting among middle-aged women: the relationship between menopausal status, hormone replacement therapy, and exercise participation. Health Psychol 1997; 16: 203-208.

20, Breslau N. Psychiatric comorbidity of smoking and nicotine dependence. Behav Genet 1995; 25: 95-101

21, Jorm AF, Rodgers B, Jacomb PA, Christensen H, Henderson S, Korten AE. Smoking and mental health: results from a community survey. Med J Aust 1999; 170: 74-77.

22, Covey LS, Glassman AH, Stetner F. Cigarette smoking and major depression. J Addict Dis 1998; 17: 35-46.

23, File SE, Kenny PL, Ouagazzal. Bimodal modulation by nicotine of anxiety in the social interaction test: role of the dorsal hippocampus. Behav Neurosci 1988; 112: 14231429.

24, Laje RP, Berman JA, Glassman AH. Depression and nicotine: preclinical and clinical evidence for common mechanisms. Curr Psychiatry Rep 2001; 3(6):470-6.

25, Michnovicz JJ, Bradlow HL. Dietary and pharmacological control of estradiol metabolism in humans. Annals New York Acad Sci 1990; 595: 291-299. 26, Li C, Samsioe G, Wilaman K, et al. Effects of norrthisterone acetate addition to estradiol in long term HRT. Maturitas 2000; 36: 139-152. 
27, Manson JE, Colditz GA, Stampfer MJ, et al. A prospective study of obesity and risk of coronary heart disease in women. N Engl J Med 1990; 322: 882-889.

28, Bray GA. Complications of obesity. Ann Intern Med 1985; 103 (6-2): 1052-1062.

29, Brown WJ, Dobson AJ, Mishra G. What is a healthy weight for middle aged women? Int J Obes 1998; 22: 520-528.

30, Editorial. Menopause and weight. Menopause 2001; 8 (4): 230-232.

31, Willett WC, Manson JE, Stampfer MJ, et al. Weight, weight change, and coronary heart disease in women. JAMA 1995; 273: 461-465. 
Table 1

Frequency of the most common somatic symptoms in relation to background factors in 6917 middle-aged women.

Each background factor was analyzed by logistic regression model dichotomized as high and low number of symptoms

Frequency of somatic symptoms
\[ \begin{array}{llllll}\text { Headache } & \text { Dizzy } & \text { Gastrointestinal } & \text { Joint } & \text { Leg/back } & \text { High vs. low } \\ & & \text { disorders }^{b} & \text { problems } & \text { pain } & \text { (8-19) vs. (0-2) }\end{array} \]

Variables

$(\%)^{\mathrm{a}} \quad(\%)$

(\%)

$(\%)$

$(\%)$

$(\%)$

OR $(95 \% \mathrm{Cl})^{\mathrm{c}}$

\begin{tabular}{|c|c|c|c|c|c|c|c|}
\hline \multicolumn{8}{|l|}{ Age } \\
\hline Age $50-53$ & 17 & 54 & 27 & 16 & 42 & 41 & 1.0 \\
\hline Age 54-57 & 43 & 47 & 27 & 19 & 46 & 47 & $1.00(0.84-1.18)$ \\
\hline Age 58-64 & 40 & 42 \#\#\# & 26 & 19 & $49 \#$ & $50 \#$ & $0.97(0.81-1.16)$ \\
\hline
\end{tabular}

\section{Marital status}

Unmarried

$\begin{array}{llll}28 & 47 & 28 & 20\end{array}$

Married

$72 \quad 47$

26

\section{Education}

$\begin{array}{lllll}\text { Basic } & 18 & 42 & 28 & 15 \\ \text { Secondary } & 47 & 47 & 27 & 18 \\ \text { University } & 35 & 49 \# \# \# & 25 & 18\end{array}$

$\begin{array}{ll}52 & 53 \\ 47 & 50 \\ 40 \# \# \# & 40 \# \# \#\end{array}$

University

Employment

$\begin{array}{lllll}\text { Full-time } & 55 & 46 & 25 & 16 \\ \text { Part-time } & 32 & 46 & 25 & 15 \\ \text { Unemployed } & 13 & 50 & 36 \text { \#\#\# } & 24 \text { \#\#\# }\end{array}$

$\begin{array}{ll}41 & 42 \\ 47 & 49 \\ 60 \# \# \# & 63 \# \# \#\end{array}$

1.0

Unemployed

60 \#\#\# 63 \#\#\#

1.17 (0.99-1.38)

Activity at work

$\begin{array}{lllll}\text { Sedentary } & 36 & 47 & 26 & 15 \\ \text { Light } & 38 & 45 & 24 & 15\end{array}$

$26 \quad 15$

1.0

$1.03(0.87-1.22)$

$52 \quad 53 \# \#$

$0.93(0.77-1.13)$

\section{Smoking status}

$\begin{array}{lllll}\text { No } & 79 & 48 & 26 & 16 \\ \text { cig. } \leq 14 / \text { day } & 13 & 44 & 28 & 15 \\ \text { cig }>\text { 15/day } & 8 & 44 \# & 31 \# & 16\end{array}$

45

46

1.0

cig. $\geq 15 /$ day

\section{Alcohol}

Light

Heavy

$\begin{array}{llll}25 & 48 & 29 & 18 \\ 62 & 45 & 25 & 16 \\ 13 & 44 & 23 \# \# \# & 17\end{array}$

\section{Exercise}

\begin{tabular}{|c|c|c|c|}
\hline No & 54 & 51 & 36 \\
\hline Light & 55 & 47 & 26 \\
\hline Vigorous & 49 & 37 \#\# & 20 \#\#\# \\
\hline
\end{tabular}

47

48

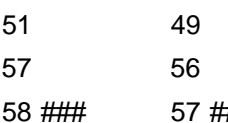

1.0

$0.60(0.52-0.71)$ ***

$0.72(0.57-0.91)$ **
$1.19(0.98-1.449$

1.0

$\begin{array}{llc}57 & 60 & 1.0 \\ 45 & 47 & 0.43(0.37-0.50) * * * \\ 34 \# \#+ & 29 \# \# \# & 0.24(0.16-0.37) * * *\end{array}$


Frequency of somatic symptoms

High vs. low

Headache Dizzy

$\begin{array}{ll}\text { Gastrointestinal } & \text { Joint } \\ \text { disorders }^{\text {b }} & \text { problems }\end{array}$

Leg/back

number of symptoms:

Variables

$(\%)^{\mathrm{a}} \quad(\%)$

(\%)

(\%)

(\%)

$(\%)$

(8-19) vs. (0-2)

OR $(95 \% \mathrm{Cl})^{\mathrm{c}}$

\section{Oophorectomy}

$\begin{array}{llllllll}\text { No } & 93 & 47 & 26 & 16 & 45 & 46 & 1.0 \\ \text { Yes } & 7 & 50 & 33 \# \# \# & 20 \# \# & 57 \# \# \# & 56 \# \# \# & 1.80(1.37-2.37) \text { *** }\end{array}$

\section{Hysterectomy}

$\begin{array}{llllllll}\text { No } & 88 & 46 & 26 & 18 & 45 & 46 & 1.0 \\ \text { Yes } & 12 & 53 \# \# \# & 33 \# \# \# & 21 \# \# & 55 \# \# \# & 55 \# \# \# & 1.89(1.52-2.34) \text { *** }\end{array}$

BMI

$\leq 25.0$

$\begin{array}{llll}59 & 46 & 25 & 13\end{array}$

$25.1-29.9$

$30 \quad 47$

$28 \quad 14$

$\geq 30$

$11 \quad 46$

29 \# 16

42

42

1.0

$51 \quad 51$

57 \#\#\# 61 \#\#\#

$1.70(1.42-2.04)$ ***

WHR

$<0.80$

$\begin{array}{llll}71 & 47 & 25 & 17\end{array}$

30 \#\#\# 18

43

44

51 \#\#\# 54 \#\#\#

1.0

$>0.80$

$29 \quad 48$

8

Increased weight more than 5 kg during the last 5 years

$\begin{array}{lllll}\text { No } & 57 & 44 & 23 & 15\end{array}$

\section{Decreased weight more than $5 \mathbf{k g}$ during the last 5 years}

$\begin{array}{lllll}\text { no } & 87 & 46 & 25 & 16 \\ \text { yes } & 13 & 50 \# & 29 \# & 20 \# \#\end{array}$

\section{Weight gain (from 25 years up to now)}

$\begin{array}{lllll}\leq 5 \mathrm{~kg} & 26 & 45 & 22 & 16 \\ 6-10 \mathrm{~kg} & 27 & 44 & 25 & 16 \\ 11-20 \mathrm{~kg} & 34 & 47 & 27 & 17 \\ >20 \mathrm{~kg} & 13 & 51 \# \# & 33 \# \# \# & 21 \# \#\end{array}$

$40 \quad 40$

53 \#\#\# 56\#\#\#

1.0

$3.15(2.73-3.64) * \star \star$

History of HT, DM, AMI, CVL or DVT

\begin{tabular}{|c|c|c|c|c|c|c|c|}
\hline No & 90 & 46 & 26 & 19 & 44 & 43 & 1.0 \\
\hline Yes & 10 & 53 \#\#\# & 43 \#\#\# & 21 & 51 \#\#\# & 58 \#\#\# & $2.22(1.88-2.61)$ *** \\
\hline \multicolumn{8}{|c|}{ With cancer } \\
\hline No & 91 & 46 & 25 & 26 & 45 & 43 & 1.0 \\
\hline Yes & 9 & 49 & 29 & $32 \#$ & $55 \# \#$ & $52 \#$ & 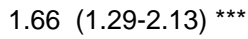 \\
\hline
\end{tabular}

a, The distribution of all women (\%) according to the variable. 
b, Gastrointestinal disorders included stomach pain, nausea, diarrhea and constipation.

\# Significant differences between the sub-groups, $\# p<0.05 ; \# p<0.01 ; \quad \# \# p<0.001$.

* Significant differences as compared with reference, $\quad$ * $p<0.05 ; \quad$ ** $p<0.01 ; \quad$ *** $p<0.001$. 
Table 2, Independent predictors for somatic symptoms in relation to different hormonal status. Results were analyzed by use of logistic forward stepwise regression model, in which 16 background variables were included.

\begin{tabular}{|c|c|c|c|}
\hline & \multicolumn{3}{|c|}{ Somatic symptoms ${ }^{b}$} \\
\hline & Total $(n=1384)$ & PMO $(n=850)$ & PMT $(n=302)$ \\
\hline Variables $^{a}$ & OR (95\% Cl) & OR (95\% Cl) & OR $(95 \% \mathrm{Cl})$ \\
\hline \multicolumn{4}{|c|}{ Marital status } \\
\hline unmarried & 1.0 & & 1.0 \\
\hline married & $0.62(0.47-0.82) * \star \star$ & & $0.48(0.27-0.86)$ * \\
\hline \multicolumn{4}{|l|}{ Education } \\
\hline basic & 1.0 & 1.0 & \\
\hline secondary & $1.57(1.15-2.10)$ * & $1.60(1.11-2.13)$ * & \\
\hline university & $1.19(0.94-1.50)$ & $1.35(0.91-2.00)$ & \\
\hline \multicolumn{4}{|l|}{ Employment } \\
\hline full-time & 1.0 & 1.0 & \\
\hline part-time & $1.31(0.98-1.76)$ & $1.20(0.81-1.79)$ & \\
\hline unemployed & 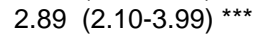 & 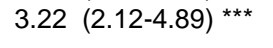 & \\
\hline \multicolumn{4}{|c|}{ Activity at work } \\
\hline Sedentary & & & 1.0 \\
\hline light & & & $0.52(0.28-0.94)$ * \\
\hline heavy & & & $1.09(0.58-2.07)$ \\
\hline \multicolumn{4}{|l|}{ Exercise } \\
\hline no & 1.0 & 1.0 & 1.0 \\
\hline Light & $0.51(0.39-0.66) * \star \star$ & $0.52(0.36-0.74) * \star \star$ & $0.42(0.24-0.73)$ ** \\
\hline Vigorous & $0.23(0.11-0.50)$ *** & $0.31(0.12-0.82)$ * & $0.22(0.06-0.91)$ * \\
\hline \multicolumn{4}{|l|}{ BMI } \\
\hline$\leq 25.0$ & & 1.0 & \\
\hline $25.1-29.9$ & & $0.97(0.65-1.44)$ & \\
\hline$\geq 30$ & & $1.89(1.12-3.19)$ * & \\
\hline \multicolumn{4}{|c|}{ Increased weight $5 \mathrm{~kg}$ during the last 5 years } \\
\hline no & 1.0 & 1.0 & 1.0 \\
\hline yes & $2.56(2.00-3.28) * * *$ & $2.37(1.64-3.44) * * *$ & $2.15(1.28-3.61) * \star$ \\
\hline \multicolumn{4}{|c|}{ Weight gain (from 25 years up to now) } \\
\hline$\leq 5 \mathrm{~kg}$ & 1.0 & 1.0 & 1.0 \\
\hline $6-10 \mathrm{~kg}$ & $1.33(1.02-1.73)$ * & $1.15(0.75-1.78)$ & $1.18(0.76-1.82)$ \\
\hline $11-20 \mathrm{~kg}$ & $1.68(1.31-2.15)^{\star \star \star}$ & $1.64(1.10-2.42)$ * & $1.65(1.07-2.53)$ * \\
\hline$>20 \mathrm{~kg}$ & $3.75(2.72-5.16) * \star \star$ & $3.61(2.27-5.75) * * \star$ & $6.01(3.00-12.03) * * \star$ \\
\hline \multicolumn{4}{|c|}{ History of $H T, D M, A M I, C V L$ or DVT } \\
\hline no & 1.0 & 1.0 & 1.0 \\
\hline yes & $1.66(1.26-2.19) * \star \star$ & $1.67(1.16-2.41)^{\star *}$ & $2.39(1.34-4.27)$ ** \\
\hline \multicolumn{4}{|l|}{ With cancer } \\
\hline no & 1.0 & 1.0 & \\
\hline yes & $2.04(1.29-3.22) * \star$ & $2.44(1.39-4.27) * \star$ & \\
\hline
\end{tabular}


a. Variables with a statistical significance were presented in the table.

b, Odds ratio was compared between the number of symptoms with high 8-19 (severe) and low 0-2 (absence/slight).

* Significant difference of OR as compared with reference, ${ }^{\star} p<0.05 ;{ }^{\star \star} p<0.01 ;{ }^{\star \star \star} p<0.001$. 
Table 3

Frequency of the most common psychological symptoms in relation to background factors in 6917 middle-age women. Each background factor was analyzed by logistic regression model dichotomized as high and low number of symptoms

\begin{tabular}{|c|c|c|c|c|c|c|c|}
\hline \multicolumn{7}{|c|}{ Frequency of psychological symptoms } & \multirow{2}{*}{$\begin{array}{c}\text { High vs. low } \\
\text { number of symptoms: } \\
(5-10) \text { vs. }(0-1)\end{array}$} \\
\hline & & Fatigue & Sleeping & Irritation & Depressive & Overstressed & \\
\hline Variables & $(\%)^{a}$ & yes $(\%)$ & yes $(\%)$ & yes $(\%)$ & yes $(\%)$ & yes $(\%)$ & OR $(95 \% \mathrm{Cl})^{b}$ \\
\hline \multicolumn{8}{|l|}{ Age } \\
\hline age $50-53$ & 17 & 66 & 42 & 48 & 56 & 46 & 1.0 \\
\hline age $54-57$ & 43 & 62 & 45 & 43 & 55 & 45 & $0.87(0.75-1.01)$ \\
\hline age $58-64$ & 40 & $56 \# \# \#$ & 45 & $40 \# \# \#$ & $51 \#$ & $36 \# \# \#$ & $0.70(0.60-0.82) * \star *$ \\
\hline \multicolumn{8}{|c|}{ Marital status } \\
\hline unmarried & 28 & 64 & 46 & 45 & 61 & 45 & 1.0 \\
\hline married & 72 & $60 \# \# \#$ & 43 & $42 \#$ & $51 \#$ & 41 \# & $0.65(0.56-0.74) * \star \star$ \\
\hline \multicolumn{8}{|l|}{ Education } \\
\hline basic & 18 & 54 & 45 & 40 & 51 & 30 & 1.0 \\
\hline secondary & 47 & 59 & 44 & 44 & 54 & 39 & $1.28(1.07-1.54) * \star$ \\
\hline university & 35 & $66 \# \# \#$ & 43 & 43 & 54 & 53 \#\#\# & $1.4681 .28-1.67) * \star *$ \\
\hline \multicolumn{8}{|c|}{ Employment } \\
\hline full-time & 55 & 63 & 41 & 42 & 51 & 51 & 1.0 \\
\hline part-time & 32 & 57 & 44 & 42 & 53 & 37 & $0.84(0.73-0.97)$ * \\
\hline unemployed & 13 & $62 \# \# \#$ & $56 \# \# \#$ & 48 \#\# & $65 \# \# \#$ & $25 \# \# \#$ & $1.37(1.16-1.62) * \star *$ \\
\hline \multicolumn{8}{|c|}{ Activity at work } \\
\hline sedentary & 36 & 63 & 44 & 42 & 54 & 44 & 1.0 \\
\hline light & 38 & 61 & 41 & 42 & 52 & 45 & $1.07(0.93-1.24)$ \\
\hline heavy & 26 & $57 \# \# \#$ & 44 & 42 & 52 & 45 & $1.09(0.92-1.28)$ \\
\hline \multicolumn{8}{|l|}{ Exercise } \\
\hline no & 79 & 76 & 56 & 47 & 66 & 48 & 1.0 \\
\hline light & 13 & 60 & 44 & 43 & 53 & 42 & $0.56(0.48-0.64) * \star \star$ \\
\hline vigorous & 8 & 49 \#\#\# & 33 \#\#\# & $37 \#$ & $50 \# \# \#$ & $36 \# \#$ & $0.44(0.33-0.60) * \star *$ \\
\hline \multicolumn{8}{|c|}{ Smoking status } \\
\hline no & 25 & 60 & 44 & 42 & 52 & 42 & 1.0 \\
\hline cig.<14/day & 62 & 61 & 42 & 45 & 59 & 42 & $1.18(0.99-1.40)$ \\
\hline cig. $>15 /$ day & 13 & $71 \# \# \#$ & 46 & $46 \#$ & $62 \# \#$ & 45 & $1.63(1.23-2.17) * \star *$ \\
\hline \multicolumn{8}{|c|}{ Alcohol consumption } \\
\hline no & 54 & 61 & 44 & 41 & 54 & 37 & 1.0 \\
\hline light & 55 & 58 & 42 & 42 & 52 & 43 & $0.99(0.86-1.13)$ \\
\hline heavy & 49 & $62 \#$ & 45 & 44 & 53 & $42 \# \# \#$ & $1.10(0.90-1.35)$ \\
\hline
\end{tabular}




\section{Frequency of psychological symptoms}

Fatigue Sleeping Irritation
High vs. low Depressive Overstressed number of symptoms: (5-10) vs. (0-1)

Variables $(\%)^{a} \quad$ yes (\%) $\quad$ yes (\%) $\quad$ yes (\%)
OR $(95 \% \mathrm{Cl})^{\text {b }}$

\section{Oophorectomy}

$\begin{array}{lllllllll}\text { no } & 93 & 61 & 44 & 43 & 54 & 43 & 1.0 & \\ \text { yes } & 7 & 63 & 47 & 45 & 54 & 43 & 1.25(0.98-1,60)\end{array}$

\section{Hysterectomy}

$\begin{array}{llllllll}\text { no } & 88 & 60 & 44 & 42 & 53 & 42 & 1.0 \\ \text { yes } & 12 & 64 \# & 45 & 47 \# \# & 55 & 45 & 1.24(1.03-1.50) \text { * }\end{array}$

BMI

$<25.0$

$60 \quad 44$

\section{1}

\section{3}

$45 \quad 54$

$25.1-29.9 \quad 30$

$62 \quad 44$

45 \#

57 \#

42

1.0

$\geq 30$

66 \#\# 46

42

44

$1.27(1.09-1.49)$ **

1.37 (1.14-1.69) **

\section{WHR}

$<0.80$

71

60

44

42

53

42

1.0

$>0.80$

64 \#

45

$57 \#$

43

$1.23(1.09-1.39) * * *$

Decreased weight more than 5 kg during the last 5 years

$\begin{array}{llllllll}\text { no } & 57 & 58 & 42 & 41 & 51 & 41 & 1.0 \\ \text { yes } & 43 & 65 \# \# \# & 48 \# \# \# & 42 & 60 \# \# \# & 42 & 1.32(1.09-1.60) \text { ** }\end{array}$

\section{Increased weight more than $5 \mathbf{k g}$ during the last 5 years}

$\begin{array}{llllllll}\text { no } & 87 & 55 & 41 & 38 & 50 & 39 & 1.0 \\ \text { yes } & 13 & 68 \# \# \# & 48 \# \# \# & 49 \# \# \# & 59 \# \# \# & 47 \# \# \# & 1.93(1.70-2.19) \text { *** }\end{array}$

\section{Weight gain (from 25 years up to now)}

\begin{tabular}{|c|c|c|c|c|c|c|c|}
\hline$\leq 5 \mathrm{~kg}$ & 26 & 59 & 42 & 39 & 51 & 41 & 1.0 \\
\hline $6-10 \mathrm{~kg}$ & 27 & 57 & 43 & 40 & 50 & 41 & $0.95(0.80-1.12)$ \\
\hline $11-20 \mathrm{~kg}$ & 34 & 60 & 43 & 45 & 53 & 42 & $1.12(0.95-1.32)$ \\
\hline$>20 \mathrm{~kg}$ & 13 & 70 \#\#\# & 47 & $48 \# \# \#$ & $58 \# \# \#$ & 46 & $1.71(1.37-2.14) * \star \star$ \\
\hline \multicolumn{8}{|c|}{ History of $H T, D M, A M I, C V L$ or DVT } \\
\hline & 90 & 60 & 44 & 43 & 54 & 42 & 1.0 \\
\hline yes & 10 & $67 \#$ & 52 \#\# & 44 & $61 \#$ & $46 \#$ & $1.27(1.10-1.46) * \star \star$ \\
\hline \multicolumn{8}{|c|}{ With cancer } \\
\hline no & 91 & 59 & 43 & 42 & 52 & 42 & 1.0 \\
\hline yes & 9 & 66 & 47 & 45 & 57 & 45 & 1.22 (0.97-1.52) \\
\hline
\end{tabular}


a, The distribution of the all women (\%) according to the variable.

\# Significant differences between the sub-groups, \# $\mathrm{p}<0.05 ; \#$ \# $<0.01 ; \quad$ \#\# $\mathrm{p}<0.001$.

* Significant differences as compared with reference, $\quad{ }^{*} p<0.05 ; \quad * * p<0.01 ; \quad$ *** $p<0.001$. 
Table 4, Independent predictors for psychological symptoms in relation to different hormonal status. Results were analyzed by use of logistic forward stepwise regression model, in which 16 background variables were included.

\section{Psychological symptoms ${ }^{b}$}

\section{Total $(n=1841)$}

PMO ( $n=1085)$

PMT (n= 429)

Variables $^{a}$

OR $(95 \% \mathrm{Cl})$

OR $(95 \% \mathrm{Cl})$

OR $(95 \% \mathrm{Cl})$

\section{Marital status}

unmarried

married

1.0

$0.74(0.59-0.92) * *$

\section{Education}

basic

secondary

university

\section{0}

$1.46(1.08-1.96)$ *

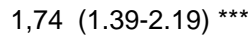

Employment

\section{full-time}

part-time

unemployed

$$
1.0
$$

$0.95(0.76-1.19)$

$1.35(1.04-1.75)$ *

\section{Exercise}

no

light

1.0

$0.61(0.50-0.75)$ ***

vigorous
1.0

$1.55(1.05-2.29)$ *

$1.76(1.31-2.36)$ ***

1.0

0.88 (0.66-1.18)

$1.68(1.20-2.37)$ **

1.0

$0.58(0.45-0.76)$ ***

$0.53(0.28-1.00)$ *

1.0

$0.56(0.37-0.85)$ **

$0.28(0.10-0.79)$ *

\section{Smoking status}

no

$$
1.0
$$

cig. $\leq 14 /$ day

$$
1.29(0.98-1.71)
$$

1.0

cig. $\geq 15 /$ day

$1.75(1.14-2.69)$ *

Increased weight 5 kg during the last 5 years

$\begin{array}{llll}\text { no } & 1.0 & 1.0 & 1.0 \\ \text { yes } & 1.71(1.40-2.08) * \star * & 1.69(1.31-2.18) * \star * & 1.57(1.03-2.40) \text { * }\end{array}$

Weight gain (from 25 years up to now)

$\begin{array}{ll}\leq 5 \mathrm{~kg} & 1.0 \\ 6-10 \mathrm{~kg} & 1.02(0.83-1.25) \\ 11-20 \mathrm{~kg} & 1.13(0.93-1.38) \\ >20 \mathrm{~kg} & 1.60(1.22-2.09)\end{array}$

1.0

$0.85(0.60-1.22)$

$1.07(0.75-1.53)$

$2.20(1.22-3.96)$ **

\section{With cancer}

$\begin{array}{lll}\text { no } & 1.0 & 1.0 \\ \text { yes } & 1.51(1.03-2.20) * & 1.83(1.15-2.90) \text { * }\end{array}$

a. Variables with a statistical significance were presented in the table.

b, Odds ratio was compared between the number of symptoms with high 5-10 (severe) and low 0-1 (absence/slight).

* The significant differences of the ORs are marked, * $p<0.05 ;{ }^{\star \star} p<0.01 ;{ }^{\star \star \star} p<0.001$. 